\title{
Internacionalização da Educação Superior como indicador do Sinaes: de qual qualidade estamos falando?
}

\author{
Internationalization of Higher Education as an indicator of Sinaes: \\ what quality are we talking about?
}

\author{
Internacionalización de la Educación Superior como indicador de las campanas: \\ de qué calidad estamos hablando?
}

José VIEIRA DE SOUSA*

\begin{abstract}
RESUMO
O processo da internacionalização tem ganhado centralidade nos debates sobre a qualidade das instituições de educação superior (IES), tornando-se elemento indispensável ao crescimento científico e cultural entre países das várias regiões do mundo. Como integrador das dimensões internacional, intercultural e global às atividades próprias das IES - ensino, pesquisa e extensão -, esse processo configura-se, cada vez mais, como uma forma de induzir a qualidade, razão pela qual, ao invés de acontecer espontaneamente, precisa ser estimulado por políticas institucionais. Partindo dessas premissas, o objetivo do artigo é investigar as estratégias de internacionalização adotadas por um conjunto de cinco universidades federais apontadas nos indicadores de qualidade do Sistema Nacional de Avaliação da Educação Superior (Sinaes), instituído pela Lei $\mathrm{n}^{\mathrm{O}}$ 10.861/2014, entre as doze melhores IES do Brasil, no ano de 2014. No ámbito do Sinaes, o indicador relativo à internacionalização faz parte do eixo de avaliação do Desenvolvimento Institucional da IES, propondo-se a verificar a coerência entre o seu Plano de Desenvolvimento Institucional (PDI) e as políticas institucionais, no caso deste trabalho, das cinco universidades selecionadas e sua interface com a política do Sinaes. A reflexão proposta considera, por um lado, a complexidade que envolve o conceito de internacionalização associado à educação superior e as estratégias adotadas pelas IES e, por outro, que a internacionalização demanda a formulação e avaliação de metas sintonizadas, dentre outros, com as exigências da globalização articuladas às diferentes formas de sua participação no processo.

Palavras-chave: Educação Superior. Internacionalização. Qualidade. Sinaes.
\end{abstract}

\begin{abstract}
The process of internationalization has gained centrality in the debates on the quality of higher education institutions, becoming an indispensable element for scientific and cultural growth among countries in the various regions of the world. As an integrator of the international, intercultural and global dimensions of activities - teaching, research and extension - this process is becoming more and more a way of inducing quality, which is why, instead of happening spontaneously, Needs to be stimulated by institutional policies. Based on these premises, the objective of this article is to investigate the internationalization strategies adopted by a group of five federal universities, as pointed out in the quality indicators of the National System for the Evaluation of Higher Education (Sinaes), instituted by Law No. 10.861/2014, In Sinaes, the internationalization indicator is part of the IES Institutional Development evaluation axis, aiming at verifying the coherence between its Institutional Development Plan and the institutional policies, in the case of this work, the five selected universities and their interface with Sinaes policy. The proposed reflection considers, on the one hand, the complexity involved in the concept of internationalization associated with higher education and the strategies adopted by the IES and, on the other, that internationalization demands the formulation and evaluation of tuned goals, among others, with the requirements the different forms of their participation in the process.
\end{abstract}

Keywords: Higher Education. Internationalization. Quality. Sinaes.

\section{RESUMEN}

El proceso de la internacionalización ha ganado centralidad en los debates sobre la calidad de las instituciones de educación superior (IES), convirtiéndose en un elemento indispensable para el crecimiento científico y cultural entre países de las distintas regiones del mundo. Como integrador de las dimensiones internacional, intercultural y global a las actividades propias de las IES - enseñanza, investigación y extensión -, este proceso se configura cada vez más como una forma de inducir la calidad, razón por la cual, en lugar de ocurrir espontáneamente, necesita ser estimulado por políticas institucionales. A partir de estas premisas, el objetivo del artículo es investigar las estrategias de internacionalización adoptadas por un conjunto de cinco universidades federales apuntadas en los indicadores de calidad del Sistema Nacional de Evaluación de

\footnotetext{
* Licenciado em Pedagogia pela Associação de Ensino Unificado do Distrito Federal e Letras pela Universidade de Brasília (UnB), mestre em Educação e doutor em Sociologia pela UnB. Professor da Universidade de Brasília, onde realiza estudos sobre avaliação, expansão, democratização e acesso à educação superior. Coorganizador da Coleção Políticas Públicas de Educação, publicada pelas Editoras Autores Associados (2011, 2013 e 2014), Líber Livro (2012) e Fino Traço (2015 e 2016). Coordenador do Grupo de Trabalho Política de Educação Superior da Associação de Pós-Graduação e Pesquisa em Educação (Anped), nos biênios 2013-2015 e 2015-2017. Coordenador do Grupo de Estudos de Políticas de Avaliação de Educação Superior (Gepaes/UnB. Pesquisador da Rede Universitas/Br - Projeto Políticas da Expansão da Educação Superior no Brasil (OBEDUC/Capes). E-mail: <sovieiral@gmail.com>.
} 
la Educación Superior (Sinaes), instituido por la Ley no 10.861/2014, entre las doce mejores IES de Brasil, en el año 2014. En el ámbito del Sinaes, el indicador relativo a la internacionalización forma parte del eje de evaluación del Desarrollo Institucional de la IES, proponiendo verificar la coherencia entre su Plan de Desarrollo Institucional (PDI) y las políticas institucionales, en el caso de este trabajo, de las cinco universidades seleccionadas y su interfaz con la política del Sinaes. La reflexión propuesta considera, por un lado, la complejidad que implica el concepto de internacionalización asociado a la educación superior y las estrategias adoptadas por las IES y, por otro, que la internacionalización demanda la formulación y evaluación de metas sintonizadas, entre otros, con las exigencias de la globalización articuladas a las diferentes formas de su participación en el proceso.

Palabras clave: Educación Superior. Internacionalización. Calidad. Sinaes.

\section{CONSIDERAÇÕES INICIAIS}

O objetivo deste artigo é analisar resultados de estudo sobre a política de internacionalização adotada pelas cinco universidades federais apontadas nos indicadores de qualidade do Sistema Nacional de Avaliação da Educação Superior (Sinaes), instituído pela Lei no 10.861/2014 (BRASIL, 2004), como as melhores avaliadas no Brasil, no ano de $2014^{1}$.

As instituições de educação superior (IES) selecionadas para o estudo foram: Universidade Federal do Rio Grande do Sul (UFRGS), Universidade Federal da Integração Latino-Americana (UNILA), Universidade Federal de Minas Gerais (UFMG), Universidade Federal de São Paulo (UNIFESP) e Universidade Federal de Santa Catarina (UFSC). Três dessas IES estão situadas na Região Sul e as outras duas na Região Sudeste.

Essas universidades foram escolhidas com base em dados e informações divulgados pelo Instituto Nacional de Estudos e Pesquisas Educacionais Anísio Teixeira (INEP), em seu site (http://portal.inep.gov.br/). No referido ano, esse órgão divulgou as doze universidades brasileiras que tiveram melhores desempenhos em vários indicadores oficiais, incluindo o Índice Geral de Cursos $(\mathrm{IGC})^{2}$ igual a 5 , conceito máximo definido na política do Sinaes, constando desse conjunto as IES eleitas para o estudo.

Areflexão proposta enfatiza o tema internacionalização na educação superior, examinando estratégias adotadas pelas cinco universidades anteriormente citadas, considerando que ele é um indicador da qualidade defendida pela política do Sinaes.

A Tabela 1, abaixo, apresenta as siglas das doze universidades e os critérios adotados pelo INEP para divulgá-las como as melhores avaliadas, à época. Nela estão grifadas as siglas e os indicadores de qualidade atribuídos as cinco IES definidas para o estudo, ora relatado.

Tabela 1. Indicadores de Qualidade das doze melhores IES do Brasil (2014)

\begin{tabular}{lccccccccc}
\hline $\begin{array}{c}\text { Sigla } \\
\text { da IES }\end{array}$ & $\begin{array}{c}\text { Nr. de } \\
\text { cursos }\end{array}$ & Alfa* & $\begin{array}{c}\text { Conceito } \\
\text { Graduação }\end{array}$ & Beta** & $\begin{array}{c}\text { Conceito } \\
\text { Mestrado }\end{array}$ & Gama\# & $\begin{array}{c}\text { Conceito } \\
\text { Doutorado }\end{array}$ & $\begin{array}{c}\text { IGC } \\
\text { Contínuo }\end{array}$ & $\begin{array}{c}\text { IGC } \\
\text { faixa }\end{array}$ \\
\hline UNICAMP & 43 & 0,3 & 3,0 & 0,3 & 4,9 & 0,5 & 4,9 & 4,380 & 5 \\
UFRGS & 54 & 0,4 & 3,4 & 0,3 & 4,9 & 0,4 & 5,0 & 4,349 & 5 \\
UNILA & 3 & 0,9 & 4,3 & 0,1 & 4,0 & 0,0 & 0,0 & 4,247 & 5 \\
UFMG & 57 & 0,5 & 3,4 & 0,2 & 4,9 & 0,3 & 4,9 & 4,190 & 5 \\
UNIFESP & 26 & 0,3 & 3,0 & 0,3 & 4,6 & 0,3 & 4,8 & 4,189 & 5 \\
UFSC & 56 & 0,5 & 3,3 & 0,2 & 4,8 & 0,3 & 4,9 & 4,129 & 5 \\
UFRJ & 59 & 0,4 & 3,1 & 0,2 & 4,8 & 0,3 & 4,9 & 4,114 \\
UFV & 58 & 0,5 & 3,5 & 0,2 & 4,7 & 0,2 & 4,9 & 4,101 & 5 \\
UFABC & 16 & 0,6 & 3,9 & 0,3 & 4,3 & 0,1 & 4,5 & 4,081 \\
UFLA & 21 & 0,5 & 3,5 & 0,2 & 4,7 & 0,2 & 4,8 & 4,058 \\
UnB & 52 & 0,5 & 3,5 & 0,2 & 4,6 & 0,2 & 4,7 & 4,015 \\
UFSCar & 47 & 0,5 & 3,5 & 0,2 & 4,5 & 0,3 & 4,8 & 5 \\
\hline
\end{tabular}

* Proporção de Graduandos; ** Proporção de mestrandos - Equivalente; \# Proporção de Doutorandos - Equivalente.

Fonte: $<$ http://portal.inep.gov.br/>.

\footnotetext{
${ }^{1}$ Em 2014, a Universidade Estadual de Campinas (Unicamp) foi a primeira colocada entre as doze melhores IES avaliadas pelos critérios do INEP, mas não foi incluída no estudo discutido nesse artigo por não ser federal.
}

\footnotetext{
2 O Índice Geral de Cursos (IGC) é um indicador de qualidade utilizado, a partir de 2008 pelo Estado, para a dispensa da avaliação in loco de cursos e de instituições, a depender da decisão do marco regulatório.
} 
O campo da educação superior brasileira é bastante heterogêneo, sendo possível nele identificar segmentos institucionais diversos, dotados de características bem distintas e peculiares, tanto no setor público quanto no setor privado. Dessa forma, ele revela uma dinâmica extremamente complexa marcada, sobretudo, pelas instituições que o compõem. (SOUSA, 2013). Em consequência, qualquer análise ou avaliação que se faça a seu respeito requer a compreensão de realidades institucionais bastante diferenciadas.

Por sua vez, a preocupação com a avaliação do campo da educação superior brasileira vem sendo expressa por diversos pesquisadores do tema (BERTOLIN, 2011; DIAS SOBRINHO, 2010; LEITE, 2008; PEIXOTO, 2011; RISTOFF, 2008; SOUSA, 2012, 2016). Tal preocupação justifica-se, dentre outras razões, pelo fato de a educação superior se constituir em um dos setores de grande importância no processo de adequação do projeto político nacional à nova ordem mundial e ao desenvolvimento do país, em seus mais variados setores e dimensões. É nesse contexto interpretativo que a educação superior brasileira continua a demandar estudos que focalizem sua internacionalização à luz da política avaliativa do Sinaes.

No plano metodológico, foram investigadas as políticas de internacionalização definidas/comentadas em três documentos oficiais das cinco universidades federais eleitas: Planos de Desenvolvimento Institucional (PDI); relatório de autoavaliação produzido pela respectiva Comissão Própria de Avaliação da IES e relato institucional. A consulta a esses documentos deu-se a partir de sua disponibilização nos sites das instituições selecionadas. A opção pela análise desses documentos oficiais considera que um estudo com distintas universidades federais permite um melhor enfoque das diversas possibilidades com as quais elas lidam com a internacionalização, considerando a política do Sinaes.

$\mathrm{O}$ estudo adotou a abordagem qualitativa na perspectiva de conhecer os efeitos dessa política com ênfase nas estratégias de internacionalização adotadas pelas cinco universidades. Paralelamente, recorreu à análise documental por compartilhar da tese segundo a qual os documentos elaborados por determinado órgão ou instituição "constituem uma fonte rica e estável de dados" (RAMPAZZO, 2002, p. 52).

Do ponto de vista da interpretação dos dados, optou-se pela análise do conteúdo, considerando que o exame das mensagens reveladas nos documentos das IES possibilita elencar os indicadores de sua política de internacionalização e, a partir destes, estabelecer inferências e fazer questionamentos sobre o tema pesquisado. Para Franco (2008), a análise de conteúdo parte da mensagem, entendida como palavra, texto, gesto, silêncio ou discurso. Utilizou-se como unidade de análise temática "internacionalização", levando em conta que as informações constantes nos documentos examinados foram produzidas pelas representações sociais, conceitos, expectativas, atitudes e valores que norteiam a vida das cinco IES.

Estruturalmente o texto está organizado em quatro partes, além das considerações iniciais e finais. A primeira discute a institucionalização, os componentes e as dimensões avaliativas do Sinaes. A segunda parte aborda a relação avaliação e qualidade na educação superior brasileira, partindo da premissa de que sua construção se dá em um cenário marcado pela grande diversidade das instituições que o compõem. A terceira aborda o conceito de internacionalização, situando o debate na educação superior brasileira, apresentando alguns dados para ilustrar o debate. A última parte do texto apresenta e discute a política de internacionalização das cinco universidades estudadas, tomando como referência os registros feitos em seus documentos oficiais - PDIs, relatórios de auto avaliação e relatos institucionais.

\section{INSTITUCIONALIZAÇÃO, COMPONENTES E DIMENSÕES AVALIATIVAS DO SINAES}

Por meio das portarias MEC/SESu no 11 , de 28 de abril de 2003 (BRASIL, 2003a) e no 19, de 27 de maio de 2003 (BRASIL, 2003b), deu-se início à geração do Sinaes com a realização de estudos pela Comissão Especial de Avaliação da Educação Superior (CEA). A partir da ação dessa Comissão, a Lei no 10.861, de 14 de abril de 2004 (BRASIL, 2004) instituiu esse sistema avaliativo. Como sistema nacional, o Sinaes foi estruturado tomando como referência uma tríade de componentes, que constitui seu principal objetivo: avaliação das instituições (interna e externa), dos cursos e do desempenho dos estudantes, buscando a articulação e integração desses mesmos componentes (art. 1으).

Em decorrência do seu objetivo mais amplo, o Sinaes tem como finalidades: (i) a melhoria da qualidade da educação superior; (ii) a orientação da expansão da sua oferta; (iii) aumento permanente da sua eficácia institucional e efetividade acadêmica e social e; (iv) a promoção do aprofundamento dos compromissos e responsabilidades sociais das IES, por meio da valorização de sua missão pública, da promoção dos valores democráticos, do respeito à diferença e à diversidade, da afirmação da autonomia e da identidade institucional.

$\mathrm{Na}$ atualidade, o Sinaes figura como a principal ferramenta de avaliação da educação superior do país e requer em sua efetivação a integração de instâncias e atores responsáveis pelos processos e ações que o configuram como tal. A visão formativa da avaliação 
proposta é expressa no documento que institucionaliza o Sinaes (INEP, 2009), nos termos a seguir.

Entre os objetivos da avaliação contam-se o de conhecer as fortalezas e os problemas da instituição. [...] não basta levantar as deficiências. É também muito importante identificar as qualidades e aspectos fortes da IES. Quanto aos problemas e carências, além da verificação e da constatação, é importante identificar as causalidades, explicitar as possibilidades reais para a superação e estabelecer as ações adequadas e os meios para a transformação desejada (p. 105).

Por possuir um caráter dinâmico e estar em constante construção, o Sinaes tem incorporado novos indicadores, com vistas ao processo avaliativo a que se propõe realizar, como, por exemplo, o Índice Geral de Cursos (IGC), criado pela Portaria Normativa do MEC no 12 , de 5 de setembro de 2008 (BRASIL, 2008) . Na prática, esse índice pretende expressar, em um único número, a média dos Conceitos Preliminares de Curso (CPC) de todos os cursos da graduação somando-se às notas do mestrado e doutorado de determinada IES.

O art. $3^{\circ}$ da Lei $\mathrm{n}$ o $10.861 / 2004$ (BRASIL, 2004) estabelece dez dimensões que devem ser consideradas para a autoavaliação da IES, processo este previsto no PDI e que é substrato dos relatórios produzidos pela CPA e do próprio relato institucional $1^{4}$. Dez anos após a publicação dessa lei, a Portaria no 92, de 31 de janeiro de 2014 (BRASIL, 2014) agrupou as dez dimensões da avaliação institucional em cinco eixos. Por sua vez, a Nota Técnica no 14/2014 (INEP, 2014), de 7 de fevereiro de 2014, trata do Instrumento de Avaliação Institucional Externa do Sinaes e esclarece que o "agrupamento das dimensões em eixos visa facilitar o diálogo entre as atividades que devem ser articuladas no momento da avaliação" (p.3).

Baseadas nessa ideia, a leitura e análise das estratégias de internacionalização definidas e comentadas nos documentos oficiais das cinco universidades federais selecionadas para o estudo privilegiaram os três eixos, apresentados a seguir:

Eixo 1 - Planejamento e Avaliação Institucional: considera a dimensão 8 do SINAES (Planejamento e

\footnotetext{
3 Além do IGC, também foi incorporado ao Sinaes o Indicador de Diferença entre o Desempenho Observado e Esperado (IDD), que corresponde à diferença entre o desempenho médio do concluinte de um curso e o desempenho médio estimado para os concluintes desse mesmo curso.

4 A Portaria 92/2014 (BRASIL, 2014) prevê que as IES devam produzir, a partir de 2014, um relato institucional. Esse relato é considerado uma inovação no instrumento de Avaliação Institucional Externa, e passa a ser avaliado no Eixo 1 (Planejamento e Avaliação). Nele deverá conter um relato do PDI e, especialmente, uma síntese histórica dos processos de avaliação interna e externa da IES e do seu planejamento. Deve explicitar, igualmente, as ações acadêmico-administrativas decorrentes dos resultados das avaliações, conforme o inciso VIII, do artigo 3으, da Lei no 10.861/2004 (BRASIL, 2004).
}

Avaliação). Inclui também um Relato Institucional, que descreve e evidencia os principais elementos do seu processo avaliativo (interno e externo) em relação ao Plano de Desenvolvimento Institucional (PDI), incluindo os relatórios emanados pela Comissão Própria de Avaliação (CPA), do período que constituiu o objeto de avaliação.

Eixo 2 - Desenvolvimento Institucional: contempla as dimensões 1 (Missão e o Plano de Desenvolvimento Institucional) [...];

Eixo 3 - Políticas Acadêmicas: abrange as dimensões 2 (Políticas para o Ensino, Pesquisa e Extensão) [...] (INEP, 2014, p. 3 - grifos nossos) $)^{5}$.

Por último, cabe ressaltar que, em termos de qualidade e para fins dos conceitos de avaliação do Sinaes, compreendem-se como satisfatórias as avaliações com resultado igual ou superior a 3 (três) e insatisfatórias as avaliações com resultado 1 ou 2 .

\section{AVAliaÇÃo E QUALIDAdE NA EDUCAÇÃO SUPERIOR BRASILEIRA: DESENHANDO CENÁRIOS}

Em uma perspectiva mais ampla, é possível agregar as várias tendências de avaliação em duas grandes correntes (DIAS SOBRINHO, 2010). De acordo com o autor, mostrando-se centralizadora, funcional, contábil, operacional e de resultados, uma das correntes interpretativas da avaliação tem como propósito a regulação e como meio o controle, assentado em instrumentos estandardizados. Em uma perspectiva contrária, a outra corrente é voltada para a emancipação, processando-se por mecanismos avaliativos que visam à compreensão e o aperfeiçoamento das práticas da instituição.

Nessa segunda abordagem, a avaliação assume um caráter formativo, participativo e de efetividade tanto social quanto científica. Belloni e Belloni (2003) acrescentam que, nessa perspectiva epistemológica, a avaliação estimula o desenvolvimento de processos institucionais internos. Ao fazê-lo, demanda que os resultados obtidos sejam divulgados para todos os membros da comunidade acadêmica, de maneira que possam instigar e fomentar transformações, quando utilizados pelos gestores.

\footnotetext{
${ }^{5}$ O Eixo 2 contas com outra dimensão que, no entanto, devido ao objetivo do estudo, não foi explorada (3 - Responsabilidade social da instituição), enquanto o Eixo 3 tem outras duas outras dimensões que, pela mesma razão, não foram objeto de nossas análises (4 - Comunicação com a sociedade e 9 - Políticas de Atendimento aos Discentes). Os dois outros eixos em torno dos quais se organizam as dimensões do Sinaes são: "Eixo 4 - Políticas de Gestão: compreende as dimensões 5 (Políticas de Pessoal), 6 (Organização e Gestão da Instituição) e 10 (Sustentabilidade Financeira) SINAES; Eixo 5 - Infraestrutura Física: contempla a dimensão 7 (Infraestrutura Física) do SINAES” (BRASIL. 2014, p. 3)
} 
Concretamente, avaliar implica a atribuição de valor em relação a determinado objeto ou fenômeno analisado. Em consequência disso, é razoável que as IES garantam espaços em seus documentos oficiais, como, por exemplo, os que se constituíram em fontes dos dados analisados neste estudo, de fatos que venham acompanhados desse "juízo de valor" sobre o que aconteceu com determinada meta sobre a internacionalização de suas práticas e com a efetiva ação que os gestores adotaram, como, por exemplo, se foi adequada ou não. Argumentamos isso porque, na prática, independente da sua dimensão e aplicação, avaliar pressupõe, sempre, um juízo de valor, razão pela qual compartilhamos a tese de que

[...] a avaliação é a determinação do valor ou mérito de um objeto de avaliação (seja o que for que estiver sendo avaliado) [...] é a identificação, esclarecimento e aplicação de critérios defensáveis para determinar o valor (valor ou mérito), a qualidade, a utilidade, a eficácia ou a importância do objeto avaliado em relação a esses critérios (WORTHEN, SANDERS e FITZPATRICK, 2004, p. 35).

Desse ponto de vista, a função da avaliação está diretamente relacionada à busca da qualidade, conceito que envolve grande polissemia, especialmente quando relacionado ao cenário atual da educação superior, em nível mundial e nacional. Ademais, a ausência de consenso quanto ao conceito de qualidade na literatura especializada contribui, sobremaneira, para que a definição desse termo seja revestida de grande complexidade. $\mathrm{Na}$ discussão feita mais adiante sobre as estratégias de internacionalização registradas nos PDIs, relatórios de auto avaliação e relatos institucionais da amostra reconhecemos, também, que

[...] existem diversos, diferentes e legítimos entendimentos para o termo [que] sempre podem variar no tempo e no espaço. É perfeitamente possível que a qualidade em Educação Superior tenha um significado para um grupo e, ao mesmo tempo, tenha outros, bem distintos, para outros grupos. O fato é que o entendimento de qualidade é inexoravelmente subjetivo, porque depende fundamentalmente das concepções de mundo e de Educação Superior de quem o emite [...] o entendimento de qualidade é inexoravelmente subjetivo, porque depende fundamentalmente das concepções de mundo e de Educação Superior de quem o emite (BERTOLIN, 2007, p. 155-156).

O fato é que a ausência de clareza conceitual do que seja qualidade também para o poder público pode prestarse a múltiplas interpretações por parte das IES. Além disso, é preciso lembrar que a zona de interseção entre os números da escala de conceitos de qualidade, conforme o instrumental de avaliação do INEP é, em determinado sentido, fluido.

Paralelamente à necessidade da compreensão mais objetiva do sentido de qualidade é preciso refletir sobre $o$ alcance da avaliação em uma perspectiva formativa. Isto porque a reflexão conjugada desses dois conceitos pode gerar alternativas que contribuam para clarear a polissemia que envolve o conceito de qualidade, especialmente quando o relacionamos ao cenário da educação superior, na atualidade. Nessa lógica, Sousa (2009), defende a necessidade da permanente atualização do conceito de qualidade, notadamente quando aplicado à educação, como "fator essencial para que se compreenda, de forma mais contextualizada e crítica, o seu percurso histórico-social e como ele se deixa construir" (p. 244).

Com efeito, não há na literatura especializada um consenso sobre o conceito de qualidade. Entretanto, há treze anos, o Brasil conta com uma política pública de avaliação da educação superior (Sinaes) que visa promover a qualidade desse nível educacional no país, seja estimulando a cultura da autoavaliação, seja fomentando ações de regulação. A Lei no 10.861/2004

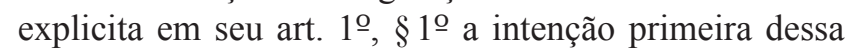
política avaliativa:

O SINAES tem por finalidades a melhoria da qualidade da educação superior, a orientação da expansão da sua oferta, o aumento permanente da sua eficácia institucional e efetividade acadêmica e social e, especialmente, a promoção do aprofundamento dos compromissos e responsabilidades sociais das instituições de educação superior, por meio da valorização de sua missão pública, da promoção dos valores democráticos, do respeito à diferença e à diversidade, da afirmação da autonomia e da identidade institucional (BRASIL, 2004).

Depreende-se do conteúdo da citação apresentada, que a melhoria da qualidade está no cerne da finalidade do Sinaes como política pública de avaliação da educação superior, pautando constantemente os discursos políticos e técnicos de diferentes segmentos sociais. Na produção desses discursos, ocorre a defesa generalizada da importância da avaliação, em suas diferentes expressões, para o alcance da qualidade nesse nível educacional. Ademais, sendo a qualidade o princípio fundante do Sinaes, geralmente se quer compreender o seu sentido e se as estratégias traçadas para alcançá-la mostram-se adequadas e reveladoras de indicadores que permitam a universidade proceder à sua autoavaliação, como instituição, visando identificar suas potencialidades e fragilidades.

Definida para a educação superior no país pelo Sinaes, a avaliação institucional corresponde a um processo que abrange tanto aspectos macropolíticos 
quanto pressupostos teórico-metodológicos, curriculares, pedagógicos, administrativos e materiais norteadores das atividades da IES. Subjaz à proposta desse sistema a ideia de que a avaliação institucional representa, por um lado, a oportunidade do conhecimento da realidade da IES com a indicação das suas potencialidades e fragilidades e, por outro, uma forma de prestação de contas à sociedade. Ao conjugar essas duas possibilidades, é importante que ela se mostre alinhada ao paradigma da avaliação sistêmica (DIAS SOBRINHO, 2010; PEIXOTO, 2011).

No âmbito da avaliação institucional situa-se a autoavaliação, processo que se configura como uma oportunidade para a IES construir uma compreensão mais abrangente e global de sua realidade, nas várias dimensões do trabalho que realiza. Desse ponto de vista, trata-se de um processo que extrapola a visão diagnóstica da realidade, ideia que corrobora a tese de que, além de um lugar do qual a IES fala, a autoavaliação é um caminho que ela precisa percorrer, apoiando-se em referenciais teóricos e metodológicos bem definidos. Ao percorrer esse caminho, é fundamental que a IES produza uma autoavaliação coerente e condizente como a especificidade do seu contexto, porém na perspectiva de captá-lo na relação que estabelece entre o todo e as partes, entre o que é singular e o que é geral às suas práticas. Enfim, partilhando do pressuposto segundo o qual "o uso da autoavaliação não é opcional: é, sim, matriz" (CUNHA, 2005, p. 212).

Desse ponto de vista, a finalidade precípua da autoavaliação é produzir resultados para o autoconhecimento da universidade - os quais também sejam indicativos aos seus trabalhos, além de visar tomadas de decisão internas. Em sua globalidade, ela constitui um processo que procura abarcar a complexidade da instituição, com vistas à qualidade como princípio nas várias dimensões do seu trabalho. Em consequência, no âmbito da política de avaliação instituída pelo Sinaes, cada IES assume a responsabilidade pela busca de seu contínuo aperfeiçoamento, visando o autoconhecimento de sua gestão política e pedagógica. Nesse sentido, um aspecto central é a questão do que é entendido por qualidade, que deve ser debatida de maneira associada ao "desempenho global da educação superior e das IES e na avaliação do ensino de graduação e de pós-graduação" (MOROSINI, 2001, p. 13).

\section{INTERNACIONALIZAÇÃO DA EDUCAÇÃO SUPERIOR: ALGUMAS DEMARCAÇÕES TEÓRICAS}

Conceitualmente, a internacionalização corresponde ao "processo de integrar uma dimensão inter- nacional, intercultural ou global com o objetivo, as funções ou o oferecimento do ensino pós-secundário" (KNIGHT, 2003, p.2). Nessa perspectiva, pode se manifestar de diferentes formas, como promovendo a mobilidade física dos indivíduos, a cooperação acadêmica de pesquisadores, professores e estudantes, bem como a parceria transnacional entre universidades de diferentes partes do mundo, envolvendo múltiplos atores.

$\mathrm{Na}$ educação superior a internacionalização equivale, portanto, a um movimento de grande abertura dos países às relações sociais externas visando à ampliação de competências diversas, como, por exemplo, educacionais, científicas e tecnológicas. Concretamente, ela pode se manifestar pelo crescente aumento da movimentação transnacional de pesquisadores, estudantes e professores universitários. O conhecimento mútuo gerado por esse movimento acontece em contextos igualmente diversificados: social, educacional, cultural, político, geográfico, econômico e linguístico, dentre outros.

\begin{abstract}
A internacionalização está provando ser uma ferramenta útil para ajudar as instituições a fixar pontos de referência e sair com soluções inovadoras em relação à gerência, à academia e à investigação. Esta segue sendo outra forma em que a internacionalização pode ajudar a fortalecer a qualidade das instituições de educação superior e as funções primordiais do ensino, da aprendizagem e do serviço (KNIGHT, 2005, p. 20).
\end{abstract}

Do ponto de vista histórico, a internacionalização é um fenômeno existente desde os primórdios da instituição universitária, considerando que ele pode ser encarado como fator constituinte, por exemplo, das práticas educativas da universidade medieval. Todavia, em decorrência das transformações sociais, políticas e econômicas mais recentes, é nas últimas quatro décadas que ela tem ganhado uma dimensão renovada na literatura especializada. Em consequência de sua abrangência e natureza, tem se constituído em um fenômeno com conceituação bastante complexa e multidimensional.

De acordo com Knight (2012), na discussão da internacionalização da educação é preciso se manter atento tanto aos benefícios quanto aos riscos e às consequências não intencionais desse processo. Nessa perspectiva, a autora enfatiza:

embora haja múltiplos e variados benefícios na internacionalização, manter o foco somente nos benefícios significa ignorar os riscos e as consequências negativas não intencionais envolvidas. A 
fuga de cérebros decorrente da mobilidade acadêmica internacional é um exemplo de efeito adverso. $\mathrm{O}$ atual conceito de circulação de cérebros não reconhece a ameaça da mobilidade acadêmica nem a grande disputa por cérebros provenientes dos países situados no extremo inferior da cadeia intelectual. Além disso, a busca pela qualificação internacional está levando à recorrente emissão de títulos fraudulentos oferecidos por fábricas de diploma (p. 65).

Para Steger (2003), o movimento de internacionalização revela as necessidades de indivíduos que vivem em uma sociedade globalizada. Trata-se de uma sociedade que demanda trocas constantes de conhecimento, visando favorecer a inter-relação de culturas e pesquisas. $\mathrm{Na}$ prática, essas trocas ultrapassam as fronteiras locais e, portanto, também propostas educacionais para a educação superior ofertada em nível local e nacional. Assim,

[...] a internacionalização tem como objetivo complementar, harmonizar e estender a dimensão local - e não dominá-la. Se essa verdade fundamental não for respeitada, existe a forte possibilidade de uma reação negativa, levando a internacionalização a ser vista como agente homogeneizante ou hegemônico. Se ignorar o contexto local, a internacionalização vai perder seu verdadeiro norte, bem como seu valor (KNIGHT, 2012, p. 64).

Nas últimas décadas, os programas de mobilidade vêm se fortalecendo e se destacando como uma das estratégias mais férteis para a cooperação acadêmica internacional. Todavia, ainda que dotados de grande relevância, esses programas constituem a parte mais visível da internacionalização, pois, na verdade, existem várias outras possibilidades. Isto porque as políticas estatais e institucionais "promovem a internacionalização diversificando e fortalecendo a base tecnológica e científica de desenvolvimento sustentável enquanto se preservam interesses nacionais e incentivos para implementar redes até a excelência na investigação tecnológica e científica (LAUS e MOROSINI, 2006, p. 148).

Na visão de Knight (2005), as razões de ser da internacionalização da educação são de naturezas diversas: políticas (estabelecimento de alianças estratégicas); econômicas (relacionadas a trocas comerciais e formação de renda); universitária (reforços diversos para as instituições educacionais) e sociocultural (compreensão mútua e desenvolvimento de ordem social e cultural). Essas razões contribuem para a compreensão de que o fenômeno da internacionalização não ocorre de maneira igual para todos os países e, muito menos, para as IES, considerando que cada uma delas possui sua dinâmica própria. Por isso, no mundo e no Brasil, a internacionalização vem acontecendo em meio a muitos desafios e tensões.

Apoiando-se nessa ideia, Lima e Maranhão (2009) classificam o fenômeno da internacionalização da educação em ativa e passiva. No primeiro caso, ela se manifesta no contexto daqueles países que investem em políticas de Estado destinadas a atrair e acolher estudantes, ofertando tantos serviços educacionais como exportando programas e instalando campi no exterior. Por sua vez, a internacionalização passiva materializa-se em países que não revelam políticas criteriosas para enviar estudantes para o exterior e que, além disso, possuem insuficientes recursos materiais e humanos para acolher e ofertar serviços educacionais.

Dados divulgados pelo INEP (2017), no ano de 2016, mostram que o Brasil contava com um total de 2.407 IES, das quais 296 (12,3\%) são públicas e 2.111 $(87,7 \%)$ vinculadas ao setor privado. Esse conjunto de instituições contava com um total de 8.048.701 matrículas, das quais $6.058 .623(75,3 \%)$ em instituições privadas e $1.990 .078(24,7 \%)$ em estabelecimentos públicos. Quando o foco da análise recai na esfera pública, verifica-se que as instituições federais apresentavam, no referido ano, 1.249.324 matrículas - o que corresponde a $15,5 \%$ do número total geral -, enquanto as estaduais contabilizavam 623.446 matrículas $(7,7 \%)$ e as municipais tinham 117.308 matrículas, equivalendo a apenas $(1,5 \%)$ do total. Dados como esses atestam a tendência histórica verificada na educação superior brasileira de restrição ao espaço público e estímulo à iniciativa privada (SOUSA, 2016).

No que tange à nacionalidade dos estudantes de outros países matriculados nas IES brasileiras, também em 2016, o referido órgão divulgou os dados mostrados no Gráfico 1 adiante.

$\mathrm{Na}$ análise apresentada no censo da educação superior de 2016 o poder público reconhece que esse nível educacional brasileiro ainda lida com baixos índices de internacionalização, como é possível depreender da declaração a seguir:

Internacionalização da educação superior no Brasil é incipiente... O Brasil conta com 15.803 estudantes estrangeiros em suas instituições de educação superior, de 174 diferentes nacionalidades, representando, entretanto, apenas $0,2 \%$ do total de matrículas (INEP, 2017, p. 31). 
Gráfico 1. Nacionalidade e número de estudantes estrangeiros em IES brasileiras (2016)

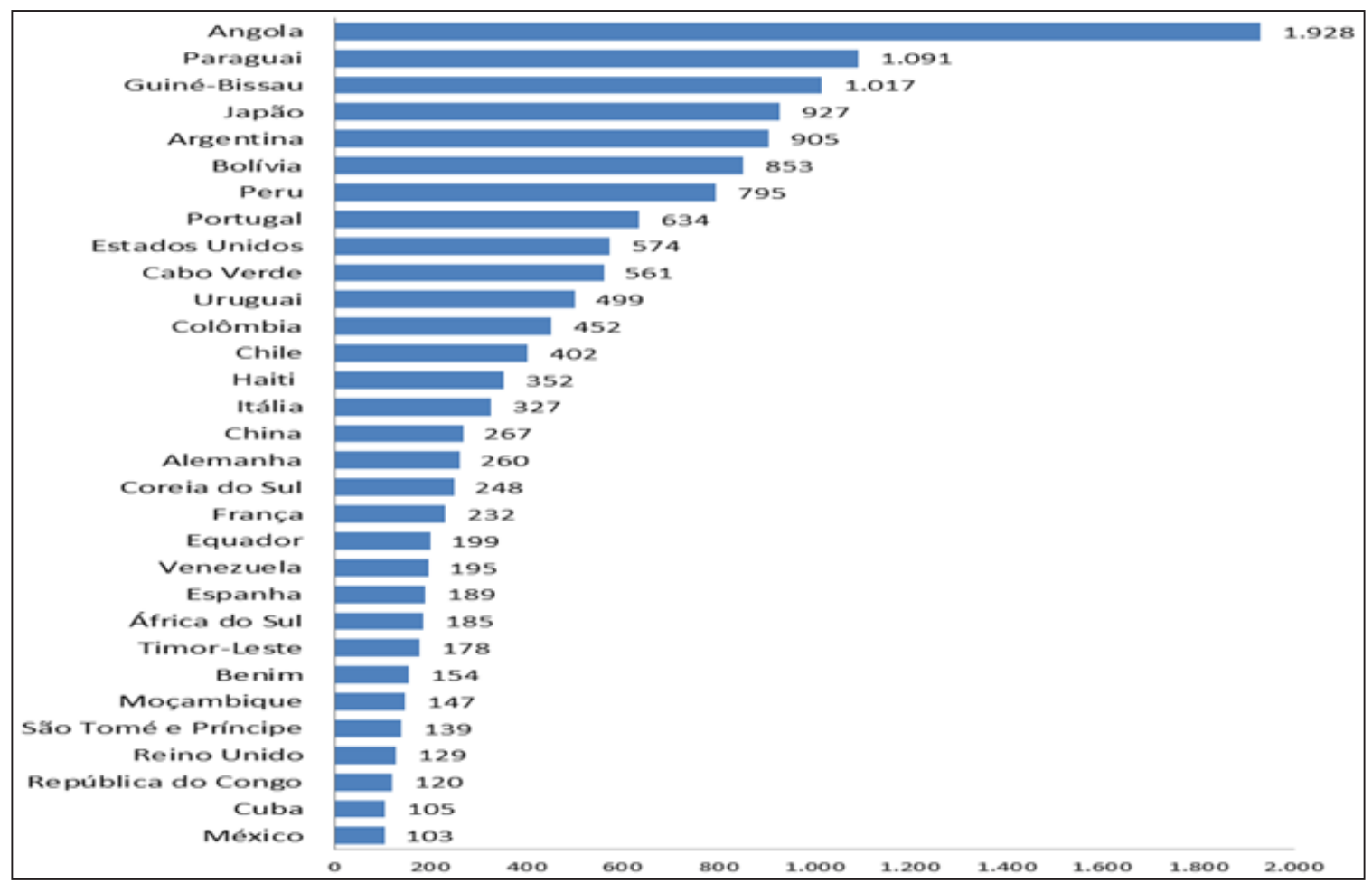

Fonte: <http:inep.gov.br/educacao_superior/censo_superior/documentos/2016/censo_superior_tabelas.pdf $>$.

\section{CAMinhos, CONTRADIÇÕES E POTENCIALIDADES DA POLÍTICA DE INTERNACIONALIZAÇÃO}

Preliminarmente, cabe destacar que a leitura dos documentos oficiais das cinco universidades federais pesquisadas permitiu constatar uma grande diversidade na construção dos mesmos. Essa diversidade mostrouse tanto em termos de sua estrutura formal como do conteúdo que expressam e, fundamentalmente, da apresentação de dados e da análise desenvolvida sobre a temática da internacionalização, como mostrado na Tabela 2. Cabe esclarecer que, no caso do relatório de auto avaliação, a primeira data refere-se ao ano de realização das ações relatadas no PDI das universidades pesquisadas e a segunda ao de sua publicação/postagem no sistema e-MEC ${ }^{6}$ na política avaliativa e regulatória do Sinaes.

\footnotetext{
${ }^{6}$ O sistema e-MEC constitui uma fonte importante de dados a respeito das IES e seus cursos, além de informar sua situação de regulação, endereços onde funcionam e os indicadores de qualidades obtidos por essas instituições nas avaliações realizadas no âmbito do Ministério da Educação.
}

Tabela 2. Documentos oficiais consultados com o número de páginas e período de vigência

\begin{tabular}{lccc}
\hline \multirow{2}{*}{ IES } & \multicolumn{3}{c}{$\begin{array}{c}\text { Documentos com o número de páginas e período } \\
\text { a que se referem }\end{array}$} \\
\cline { 2 - 4 } & PDI & $\begin{array}{c}\text { Relatório de } \\
\text { autoavaliação }\end{array}$ & $\begin{array}{c}\text { Relato } \\
\text { institucional }\end{array}$ \\
\hline UFRGS & $2011-2015-39 p$. & $\begin{array}{c}190 p .(2014) \mathrm{e} \\
116 \mathrm{p} .(2011-2015)^{1}\end{array}$ & $*$ \\
& & $251 \mathrm{p} .(2014-2015)$ & $10 \mathrm{p}$. \\
UNILA & $2013-2017-71 \mathrm{p}$. & $31 \mathrm{p}$. \\
UFMG & $2013-2017-191 \mathrm{p}$. & $206 \mathrm{p} .(2014-2015)$ & $48 \mathrm{p}$. \\
UNIFESP & $2011-2015-128 \mathrm{p} .^{2}$ & $42 \mathrm{p} .(2014-2015)$ & $*$ \\
UFSC & $2010-2014-110 \mathrm{p}$. & $320 \mathrm{p} .(2014-2015)$ & $*$
\end{tabular}

${ }^{1}$ No caso da UFRGS, constatou-se a produção de dois relatórios de autoavaliação institucional no período de interesse do estudo, razão pela qual ambos foram consultados para as análises.

${ }^{2}$ No caso da UNIFESP, foi considerado o seu PDI revisado, em 2014, conforme informação em seu site.

* Não disponível no site da IES.

No que tange ao PDI, alguns deles se configuraram em um documento amplo e aprofundado, permitindo visualizar a dinâmica da IES, a partir de um diagnóstico abrangente de sua realidade. Nesse sentido, os da UFRGS, UFMG, UNIFESP e UFSC apresentam dados sobre a definição da política de internacionalização e das estratégias adotadas para viabilizá-la. No caso da segunda mencionada, seu 
documento revela, de maneira mais objetiva, também análises dos resultados obtidos pelos seus vários campi. Por sua vez, o PDI da terceira IES elenca um conjunto de sete grandes objetivos e suas respectivas ações voltadas para a internacionalização, todavia carece de análises mais aprofundadas sobre os resultados alcançados, nos anos anteriores, com as políticas/ estratégias adotadas em relação à internacionalização. Destaca-se, a seguir, o alcance e sentido atribuídos pela IES a esse tema:

A internacionalização da UNIFESP busca a troca de experiência no aprendizado de graduação e a criação de conhecimento pelo intercâmbio com centros localizados no exterior com reconhecida postura científica e histórica no cenário universitário. [...]

[...] a inserção da UNIFESP no cenário mundial é bastante intensa, havendo cooperação direta de seus pesquisadores com os respectivos pares estrangeiros em mais de 170 instituições internacionais de natureza similar (PDI/UNIFESP, 2011, p. 83).

Todavia, apesar dessa importante declaração em seu PDI, constatou-se a ausência de informações mais consistentes sobre a avaliação da política de internacionalização tanto em relatório de autoavaliação produzido pela sua Comissão Própria de Avaliação como em seu relato institucional. Com base nos registros desse segundo documento, tudo indica que essa IES centrava esforços, à época de sua produção, na (re)estruturação de sua política de internacionalização, como se depreende do trecho a seguir, extraído do referido documento:

[...] durante o ano de 2015, a SRI [Secretaria de Relações Internacionais] trabalhou na formulação de seus regulamentos e regimento, que foi submetido e aprovado no Consu pela primeira vez. Com isso, a assinatura e renovação de convênios tornaram-se mais seguros e rápidos [...] A SRI reformulou os materiais de divulgação, bem como seu portal e formatou o seminário de internacionalização realizado em abril de 2016. Também estabeleceu o Núcleo de Idiomas (NUCLI) em conjunto com docentes do Departamento de Letras (EFLCH/Guarulhos). (RELATO INSTITUCIONAL/UNIFESP, 2015, p. 40)

A análise da política de internacionalização das cinco IES pesquisadas mostrou que quatro delas assumem em seus respectivos PDIs que estruturam ações na perspectiva de sua consolidação como universidades de classe mundial. Para tanto, concebem a internacionalização como uma importante meta a alcançar em suas práticas acadêmicas, institucionalizando-a por meio de estratégias diversas. nos últimos anos, a UFRGS constituiu o Campus Internacional, plataforma para o desenvolvimento de ações integradas e estratégicas de internacionalização. A mobilidade internacional atingiu números expressivos [...] a visibilidade e o reconhecimento internacionais posicionam a UFRGS entre as dez melhores América Latina e que merece cada vez mais atenção das Universidades de classe mundial (PDI/ UFRGS, 2011, p. 11).

O propósito de transformar a UFMG em universidade de classe mundial requer que suas atividades de internacionalização sejam fortemente alavancadas, por meio de ações e programas que demonstrem sustentabilidade [...] (PDI/UFMG, 2013, p. 71).

... essa busca é realizada pela Assessoria Internacional, que tem por objetivo consolidar a UNIFESP como instituição de classe mundial no cenário internacional da educação superior (PDI/UNIFESP, 2011, p. 84).

A UFSC deve ser administrada de modo a buscar constantemente o seu aprimoramento e chegar a um grau de desenvolvimento de uma universidade de classe mundial $[\ldots]$ buscar estudantes internacionais e de elevado nível [...] e incluir a internacionalização como parte de seu desenvolvimento institucional (PDI/ UFSC, 2010, p. 105).

Como atesta a literatura especializada, o conceito de universidade de classe mundial (UCM) se restringe a um pequeno e seleto grupo de IES no mundo. As instituições assim concebidas possuem atributos singulares e distintos do conjunto de universidade existentes nos diferentes países. Na visão de Salmi (2009), uma UCM assume um forte compromisso com o processo de internacionalização, buscando atrair e concentrar talentos, de maneira a conquistar e preservar sua excelência. Altbach (2004) acrescenta que uma universidade de classe mundial caracteriza-se, dentre outros, pelos seguintes elementos: excelência na pesquisa; liberdade de pesquisa, ensino e expressão; autonomia acadêmica; infraestrutura adequada; financiamento; diversidade e cosmopolitismo Particularmente, esse último elemento está associado à promoção de um ambiente multicultural, no qual as experiências locais dos pesquisadores, professores e estudantes convivem com aquelas desenvolvidas em outros países, contribuindo, sobremaneira, para a internacionalização da educação superior. $\mathrm{O}$ resultado concreto desse esforço é o enriquecimento tanto do ensino quanto da pesquisa, dimensão defendida nos PDIs das quatro universidades - UFRGS, UFMG, UNIFESP e UFSC -, em relação à internacionalização.

Todavia, embora essas universidades almejem se projetar como uma UCM e associem essa posição às suas estratégias de internacionalização, o exame dos seus documentos oficiais revelou que, nem sempre, tais estratégias mostram-se devidamente articuladas 
ao seu processo de autoavaliação institucional. Esse é o caso da UFSC, ainda que relacione em seu PDI 2010-2014 um conjunto de seis principais atividades desenvolvidas no âmbito do que denomina "relações interinstitucionais" e outras 14 (quatorze) grandes metas para sua internacionalização para o próximo quinquênio [2015-2019]. Constatou-se em seu extenso relatório de autoavaliação ausência de sinalizações claras de como essa IES avalia suas políticas de internacionalização, na perspectiva de apontar as potencialidades e eventuais fragilidades, em relação às mesmas. Acrescenta-se que o relato institucional da UFSC não estava disponível em seu site para consulta, conforme apontado na Tabela 2.

Na reflexão, ora proposta, a UNILA constitui um caso especial, pois se configura como uma universidade federal que pauta suas práticas em termos de internacionalização solidária. Estrategicamente localizada na tríplice fronteira entre Brasil, Argentina e Paraguai, distingue-se das demais IES pesquisadas por ter como principal objetivo promover a internacionalização da educação superior, por meio da integração regional dos povos sul-americanos. Esse compromisso decorre de sua missão, que é "contribuir para a integração solidária da América Latina e Caribe, mediante a construção e a socialização da diversidade de conhecimentos necessários para a consolidação de sociedades mais justas no contexto latino-americano e caribenho" (PDI/UNILA, 2013, p. 8).

Em decorrência de uma missão, a UNILA busca focalizar as regiões da América Latina e do Caribe, a partir de três pilares básicos: (i) integração em âmbito nacional e transnacional de forma solidária e com respeito mútuo; (ii) compromisso com a sustentabilidade, de maneira indissociável com a justiça social e o equilíbrio ambiental; (iii) perspectiva de compartilhamento de recursos e conhecimentos de natureza científica e tecnológica. Preservando sua identidade, essa IES vem formalizando solicitações de internacionalização junto a redes estrangeiras. Todavia, conforme declara em seu PDI 2013-2017, em três processos "de adesão às redes internacionais, estas manifestaram-se [sic] desfavoravelmente à adesão da UNILA, por entenderem que a Universidade não atendia às suas exigências mínimas" (PDI/UNILA, 2013, p. 111).

Quadro 1. Metas definidas pelas IES pesquisadas para a internacionalização de suas práticas acadêmicas

\begin{tabular}{|c|c|}
\hline IES & METAS DO PDI \\
\hline UFRGS & $\begin{array}{l}\text { Dedica um item intitulado "II - Missão, objetivos e metas das instituições", porém não apresenta de maneira clara metas } \\
\text { ou objetivos relacionados diretamente à internacionalização. Enfatiza a busca pela excelência e compromisso com a } \\
\text { liderança acadêmica na Região Sul do Brasil, no contexto do Mercosul, bem como para além das fronteiras do país. } \\
\text { Assume a internacionalização como um dos onze princípios de sua atuação acadêmica. (PDI/UFRGS, 2011) }\end{array}$ \\
\hline UNILA & $\begin{array}{l}\text { Enfatiza que sua política de relações internacionais pauta-se na necessidade de sua inserção internacional por meio } \\
\text { de quatro estratégias básicas: (i) cooperação com instituições congêneres de reconhecida importância mundial, com } \\
\text { destaque para as universidades latino-americanas e caribenhas; (ii) vinculação a redes universitárias, com ênfase também } \\
\text { nas regiões da América Latina e Caribe; (iii) cooperação com organizações internacionais de integração regional, como, } \\
\text { por exemplo, a Comunidade dos Estados Latino-Americanos (CELAC); (iv) cooperação com outros atores, tais como } \\
\text { organismos internacionais de cooperação, agências de fomento, movimentos sociais etc. (PDI/UNILA, 2013) }\end{array}$ \\
\hline UFMG & $\begin{array}{l}\text { Define metas específicas para o que denomina "Projetos Estruturantes", sendo a internacionalização um deles, que tem } \\
\text { como metas: (i) incrementar a mobilidade discente internacional em uma dupla direção: de seus estudantes para outras } \\
\text { universidades, e de estudantes de diferentes universidades para seus cursos; (ii) ampliar e diversificar suas parcerias com } \\
\text { universidades do exterior; (iii) criar e implementar Centros de Estudos Internacionais especializados em temáticas com } \\
\text { países de determinadas regiões do mundo, visando alargar as fronteiras do conhecimento e a ampliação da compreensão } \\
\text { entre os povos; (iv) reformular e adequar a infraestrutura de suas instâncias de internacionalização; (v) ampliar a oferta } \\
\text { de programas de mobilidade internacional para sua comunidade acadêmica. (PDI/UFMG, 2013) }\end{array}$ \\
\hline UNIFESP & $\begin{array}{l}\text { Fixa um conjunto de sete objetivos para a internacionalização, desdobrando cada um deles em ações específicas: } \\
\text { (i) elevar a qualidade da educação superior e da produção do conhecimento, atingindo níveis internacionais de excelência; } \\
\text { (ii) apoiar universidades de países com menor grau de desenvolvimento; (iii) reduzir a endogenia; (iv) preparar } \\
\text { estudantes para o mercado de trabalho globalizado; (v) melhorar os indicadores de internacionalização junto à CAPES } \\
\text { e a entidades internacionais de avaliação de IES; (vi) atuar para sua inclusão nos rankings internacionais de educação } \\
\text { superior e pesquisa; (vii) ampliar e fortalecer a estrutura de sua assessoria internacional. (PDI/UNIFESP, 2011) }\end{array}$ \\
\hline UFSC & $\begin{array}{l}\text { Situa a internacionalização na dimensão ensino, estruturando-a nas seguintes metas: (i) incrementar ações e projetos } \\
\text { de cooperação internacional; (ii) fomentar a cooperação institucional, interinstitucional, nacional e internacional em } \\
\text { redes de pesquisa de alta complexidade; (iii) estimular a participação de professores, técnico-administrativos e } \\
\text { discentes em eventos científicos internacionais para a apresentação de trabalhos; (iv) ampliar a publicação em revistas } \\
\text { indexadas internacionalmente; (v) incentivar o intercâmbio internacional de estudantes e programas de dupla titulação } \\
\text { e cotutela. (PDI/UFSC, 2010) }\end{array}$ \\
\hline
\end{tabular}

Fonte: PDIs das universidades federais pesquisadas. 
Ainda que possam variar em intensidade, de maneira geral, as metas definidas pelas cinco universidades federais estudadas em seus respectivos PDIs para a internacionalização mostram determinado grau de convergência, como mostrado no Quadro 1, retro.

De acordo com dados do Censo da Educação Superior 2016 (INEP, 2017), dentre as vinte maiores IES que possuem os maiores números de matrícula de estudantes estrangeiros, oito são públicas (seis federais e duas estaduais) e doze são vinculadas ao setor privado, sendo oito declaradas como sendo sem fins lucrativos e as outras quatro com fins lucrativos, como mostrado na Tabela 3, abaixo.

Como revelam os dados da Tabela $\mathbf{3}$, apenas duas das cinco IES pesquisadas (UNILA e UFSC) constam no universo das vinte universidades brasileiras com a mais elevada quantidade de estudantes estrangeiros, em 2016.

No que tange à avaliação institucional proposta pelo Sinaes, a análise dos documentos permite afirmar que, e maneira geral, as cinco universidades pesquisadas a reconhecem como processo importante para nortear seus processos e práticas de gestão. Entretanto, nos relatos institucionais examinados e mesmo em alguns dos relatórios de autoavaliação das IES, essa perspectiva pouco se confirmou, em relação à avaliação da política de internacionalização formulada pelas mesmas. Sendo assim, nem sempre foram encontradas evidências mais claras e contextualizadas nos dois documentos mencionados de como essa avaliação efetivamente acontece no âmbito das universidades federais pesquisadas. No que diz respeito, por exemplo, à avaliação das ações propostas para sanar determinadas fragilidades - ou para reiterar práticas que tenham se mostrado adequadas - em relação ao tema internacionalização, não há evidências mais objetivas, claras e contínuas da discussão de indicadores e resultados obtidos. Ressaltase a importância da avaliação desse tema como um indicador de qualidade das práticas acadêmicas das IES, pois isso pode contribuir significativamente para se encarar a internacionalização como um meio e não como um fim em si mesmo (KNIGHT, 2003).

Tabela 3. 20 maiores IES em número de matrículas de estudantes estrangeiros (BRASIL, 2016)

\begin{tabular}{|c|c|c|c|c|}
\hline Instituição de Educação Superior & Categoria Administrativa & $\begin{array}{l}\text { Organização } \\
\text { Acadêmica }\end{array}$ & UF & $\begin{array}{l}\text { Número de } \\
\text { Estudantes }\end{array}$ \\
\hline $\begin{array}{l}\text { Universidade da Integração Internacional da Lusofonia } \\
\text { Afro-Brasileira - UNILAB }\end{array}$ & Pública Federal & Universidade & $\mathrm{CE}$ & 1.058 \\
\hline $\begin{array}{l}\text { Universidade Federal da Integração Latino-Americana } \\
\text { - UNILA }\end{array}$ & Pública Federal & Universidade & PR & 1.001 \\
\hline Universidade Paulista - UNIP & Privada sem fins lucrativos & Universidade & SP & 713 \\
\hline Universidade de São Paulo - USP & Pública. Estadual & Universidade & SP & 458 \\
\hline Universidade Estácio de Sá - UNESA & Privada com fins lucrativos & Universidade & $\mathrm{RJ}$ & 388 \\
\hline Universidade Nove de Julho - UNINOVE & Privada sem fins lucrativos & Universidade & SP & 348 \\
\hline $\begin{array}{l}\text { Universidade Estadual Paulista Júlio de Mesquita Filho } \\
\text { - UNESP }\end{array}$ & Pública Estadual & Universidade & SP & 273 \\
\hline Centro Universitário Adventista de São Paulo - UNASP & Privada sem fins lucrativos & Centro Universitário & SP & 261 \\
\hline Universidade Federal de Santa Catarina - UFSC & Pública Federal & Universidade & $\mathrm{SC}$ & 253 \\
\hline $\begin{array}{l}\text { Centro Universitário das Faculdades Metropolitanas } \\
\text { Unidas - FMU }\end{array}$ & Privada sem fins lucrativos & Centro Universitário & SP & 241 \\
\hline Universidade Anhanguera - UNIDERP & Privada com fins lucrativos & Universidade & MS & 222 \\
\hline Universidade de Basília - UnB & Pública Federal & Universidade & DF & 209 \\
\hline Universidade Anhembi Morumbi - UAM & Privada com fins lucrativos & Universidade & SP & 187 \\
\hline Universidade do Extremo Sul Catarinense - UNESC & Privada sem fins lucrativos & Universidade & $\mathrm{SC}$ & 183 \\
\hline Universidade Pitágoras - UNOPAR & Privada com fins lucrativos & Universidade & PR & 169 \\
\hline Universidade Presbiteriana Mackenzie & Privada sem fins lucrativos & Universidade & SP & 168 \\
\hline $\begin{array}{l}\text { Pontifícia Universidade Católica de Minas Gerais - } \\
\text { PUC MINAS }\end{array}$ & Privada sem fins lucrativos & Universidade & MG & 159 \\
\hline Universidade Federal do Paraná - UFPR & Pública Federal & Universidade & PR & 151 \\
\hline Centro Universitário de Lins - UNILINS & Privada sem fins lucrativos & Centro Universitário & SP & 146 \\
\hline Universidade Federal do Rio de Janeiro - UFRJ & Pública Federal & Universidade & $\mathrm{RJ}$ & 138 \\
\hline
\end{tabular}

Fonte: <http:inep.gov.br/educacao_superior/censo_superior/documentos/2016/censo_superior_tabelas.pdf>. 
Em alguns dos documentos consultados foi possível constatar dados organizados e sistematizados por meio de processos estatísticos, bem como a apresentação de percentuais relativos às ações desenvolvidas pelas IES pesquisadas no indicador internacionalização. Todavia, esses documentos ainda revelam a necessidade de avanços no sentido de explicitar o processo avaliativo adotado, em relação à temática, nos últimos anos, visando corrigir possíveis fragilidades apontadas em sua dinâmica. Esse tipo de preocupação contribui, sobremaneira, para a compreensão da autoavaliação institucional em sua dimensão formativa, e de que ela

[...] não é a soma de pequenas análises isoladas ou a justaposição de avaliações episódicas e pontuais. Ela é a ação global, não apenas relativamente ao objeto, que é a universidade compreendida integradamente em todas as suas dimensões, relações e processos, mas também quanto ao sujeito, que é um sujeito coletivo, potencialmente todo o universo de docentes, estudantes e servidores, ou ao menos conjuntos representativos dessas três categorias, legitimados por seus pares. (DIAS SOBRINHO, 2011, p. 103).

Em suma, ainda que apresentem determinado nível de discussão, as análises registradas nos PDIs das universidades investigadas sobre a política de internacionalização, como importante elemento que contribui para construir a qualidade de suas práticas acadêmicas, elas ainda merecem ser aprofundadas à luz do que preconiza o Sinaes. Isto porque as análises em questão não se desdobram, na mesma intensidade e proporção, em avaliações das ações decorrentes da utilização dos resultados obtidos, visando sanar as fragilidades apontadas nos relatórios ou fortalecer as potencialidades neles indicadas, quanto ao tema aqui discutido - a internacionalização da educação superior.

\section{CONSIDERAÇÕES FINAIS}

Ainda que, ao longo desse artigo, determinadas ideias tenham sido recorrentes, perpassando suas diferentes seções, as considerações finais que se impõe estabelecer passa pela delimitação de três questões, consideradas centrais na discussão nele proposta.

Em relação à primeira questão, cabe destacar que, como importante indicador de qualidade proposta pela política do Sinaes, a internacionalização ainda constitui um elemento que precisa ser implementado e avaliado nas práticas acadêmicas das IES, considerando, dentre outros, dois aspectos básicos. Um deles diz respeito às estratégias adotadas pelas universidades - como as selecionadas para estudo - para promover sua internacionalização visando tanto melhorar seu desenvolvimento institucional quanto atender critérios definidos pelo Sinaes para avaliar a qualidade.

A segunda questão refere-se ao fato de que formulação e o desenvolvimento de políticas de internacionalização na sociedade globalizada acontecem no contexto de transição entre um modelo de universidade tradicional e outros de universidade do século XXI que, segundo Morosini (2014), caracteriza os contextos emergentes. Por isso, na discussão e viabilização da política de internacionalização é importante levar em conta aspectos diversos da configuração da sociedade contemporânea, tais como ambiente externo, cidadania, globalização e mundialização.

A terceira questão está relacionada aos dados levantados nos documentos oficiais das universidades federais pesquisadas (PDI, relatório de autoavaliação e relato institucional). Em geral, eles revelaram poucas evidências mais concretas de como os resultados da avaliação institucional têm contribuído para configurá-la em efetiva ferramenta de gestão da IES, como preconiza o Sinaes, em relação ao objeto da discussão feita neste artigo - internacionalização.

Podemos afirmar que o achado mais relevante do estudo realizado é verificar que quatro das cinco universidades melhor avaliadas em 2014, à luz dos critérios definidos pelo INEP - e cujos documentos oficiais foram examinados - têm empreendido esforços na direção de sua inserção no que se denomina universidade de classe mundial (UCM). Os mesmos documentos apontam como se dá a organização das IES e, fundamentalmente, como agem frente aos desafios implícitos à internacionalização da educação superior, ainda que isso seja expresso, como ressaltado antes, em níveis diversificados. Essa variação decorre de fatores diversos, como, por exemplo, a própria vivência de cada universidade investigada, bem como seu percurso histórico e os investimentos que elas podem - e devem - fazer em relação à sua autoavaliação institucional.

Por último, reiteramos ser imprescindível que as IES busquem fazer uma análise interna das políticas acadêmicas de internacionalização que concebem e implementam, na perspectiva de vislumbrar o que desejam ser e avaliar o alcance das atividades que efetivamente desenvolvem, em relação a esse indicador de qualidade definido pelo Sinaes.

\section{REFERÊNCIAS}

ALTBACH, P. G. The costs and benefits of world-class universities. International Higher Education, n. 33, 2004.

BELLONI, I.; BELLONI, J. A. Questões e Propostas para uma Avaliação institucional formativa. In: FREITAS, L. C. (Org.). Avaliação de escolas e universidades. Campinas, SP: Komedi. 2003. p. 9-34. 
BERTOLIN, J. C. G. Avaliação da qualidade do sistema de educação superior brasileiro em tempos de mercantilização - período 1994-2003. 2007. Tese (Doutorado em Educação) - Universidade Federal do Rio Grande do Sul, Porto Alegre, 2007.

BERTOLIN, J. C. G. Uma proposta de indicadores de desempenho para a educação superior brasileira. Estudos em Avaliação Educacional, São Paulo, v. 22, n. 50, p.471-490, set.-dez. 2011.

BRASIL. Lei no 10.861 , de 14 de abril de 2004. Institui o sistema Nacional de Avaliação do Ensino Superior e dá outras providências. Diário Oficial [da] República Federativa do Brasil, Brasília, DF, 15 abr. 2004.

BRASIL. Portaria no 11, de 28 de abril de 2003a. Institui a Comissão Especial de Avaliação. Diário Oficial [da] República Federativa do Brasil. Brasília, 30 abr. 2003. n. 82, Seção 2, p. 19.

BRASIL. Ministério da Educação. Portaria no 19, de 17 de maio de 2003b. Designa membros para Comissão Especial de Avaliação. Diário Oficial [da] República Federativa do Brasil, Brasília, 28 maio 2003, n. 101, Seção 2, p. 11.

BRASIL. Ministério da Educação. Portaria Normativa do MEC $\mathrm{n}^{\mathrm{o}}$ 12, de 5 de setembro de 2008. Institui o Índice Geral de Cursos da Instituição de Educação Superior (IGC). Diário Oficial [da] República Federativa do Brasil, Brasília, DF, 08 set. 2008, n. 173, Seção 1, p. 13.

BRASIL. Ministério da Educação. Portaria no 92, de 31 de janeiro de 2014. Aprova, em extrato, os indicadores do Instrumento de Avaliação Institucional Externa para os atos de credenciamento, recredenciamento e transformação de organização acadêmica, modalidade presencial, do Sistema Nacional de Avaliação da Educação Superior - SINAES. Diário Oficial [da] República Federativa do Brasil. Brasília, DF, 04 fev. 2014, seção 1, p. 5.

CUNHA, M. I. O Sistema Nacional de Avaliação da Educação Superior (SINAES): a autoavaliação como condição emancipatória. In: CUNHA, M. I. (Org.). Formatos avaliativos e concepção de docência. Campinas, SP: Autores Associados, 2005. p. 201-214.

DIAS SOBRINHO, J. Avaliação e transformações da educação superior brasileira (1995-2009): do provão ao SINAES. Avaliação, Campinas, SP, v. 15, n. 1, p. 195-224, mar. 2010.

FRANCO, M. L. P. B. Análise de conteúdo. 3. ed. Brasília: Liber, 2008.

FRANCO, M. L. P. B. Qualidade e garantia de qualidade: acreditação da educação superior. In: ROTHEN, J. C.; BARREYRO, G. B. (Org.). Avaliação da educação: diferentes abordagens críticas. São Paulo: Xamã, 2011. p. 17-41.

INSTITUTO NACIONAL DE ESTUDOS E PESQUISAS EDUCACIONAIS ANÍSIO TEIXEIRA. SINAES - Sistema Nacional de Avaliação da Educação Superior: da concepção à regulamentação, 5. ed., ampliada. Brasília: INEP, 2009.

INSTITUTO NACIONAL DE ESTUDOS E PESQUISAS EDUCACIONAIS ANÍSIO TEIXEIRA. Diretoria de Avaliação de Educação Superior. Coordenação-Geral de Avaliação de Cursos de Graduação e Instituições de Ensino
Superior. Nota Técnica no 14 /2014. Assunto: Instrumento de Avaliação Institucional Externa do Sistema Nacional de Avaliação da Educação Superior (SINAES). Disponível em: $<$ http://download.inep.gov.br/educacao_superior/avaliacao institucional/nota_tecnica/2014/nota_tecnica_n14_2014.pdf $>$. Acesso em: 24 set. 2017.

INSTITUTO NACIONAL DE ESTUDOS E PESQUISAS EDUCACIONAIS ANÍSIO TEIXEIRA. Censo da educação superior 2016. Divulgação 31 ago. 2017. Disponível em: <http:inep.gov.br/educacao_superior/censo_superior/ documentos/2016/censo_superior_tabelas.pdf>. Acesso em 14 out. 2017.

KNIGHT, J. Updated internationalization definition. International Higher Education. Boston, 2003. v. 33.

KNIGHT, J. Un modelo de interacción: respuesta a nuevas realidades y retos. In: WIT, Hans de et al. (Ed.). Educación Superior en América Latina: la dimensión internacional. Colômbia: Mayol, 2005. p. 11-42.

KNIGHT, J. Cinco verdades sobre internacionalização. International Higher Education. Center for International Higher Education, n. 69, out. 2012. Edição brasileira (Revista Ensino Superior Unicamp) publicada mediante acordo de cooperação entre Unicamp e Boston College.

LAUS, S. P.; MOROSINI, M. C. Internacionalización de la Educación Superior en Brasil. In: DE WIT, H.; JARAMILLO, J. G-A; KNIGHT, J. (Ed.). Educación Superior en America Latina: la dimensión internacional. Bogota: Banco Mundial, 2006

LEITE, D. Ameaças pós-rankings sobrevivência das CPAs e da autoavaliação. Avaliação, Campinas; Sorocaba, SP, v. 13, n. 3, p. 833-840, nov. 2008.

LIMA, M. C.; MARANHÃO, C. M. S. A. O sistema de educação superior mundial: entre a internacionalização ativa e passiva. Avaliação, Campinas; Sorocaba, SP, v. 14, n. 3, p. 583-610, nov. 2009.

MOROSINI, M. C. Qualidade da educação universitária: isomorfismo, diversidade e equidade. Interface. Fundação UNI Botucatu, UNESP, v. 5, n. 9, p. 89-102, 2001.

MOROSINI, M. C. Qualidade da educação superior e contextos emergentes. Avaliação, Campinas, Sorocaba, v. 19, n. 2, p. $385-$ 405, jul. 2014.

PEIXOTO, M. C. L. Avaliação institucional externa no Sinaes: considerações sobre a prática recente. Avaliação, Campinas; Sorocaba, SP, v. 16, n. 1, p. 11-36, mar. 2011.

RAMPAZZO, L. Metodologia científica para alunos dos cursos de graduação e pós-graduação. São Paulo: Loyola, 2002.

RISTOFF, D. I. Avaliação institucional: pensando princípios. In: BALZAN, N. C.; DIAS SOBRINHO, J. Avaliação institucional: teoria e experiências. 4. ed. São Paulo: Cortez, 2008. p. 15-36.

SALMI, J. The challenge of establishing world-class universities. World Bank Publications, 2009.

SOUSA, J. V. Qualidade na educação superior: lugar e sentido na relação público-privado. Caderno Cedes, Campinas, v. 29, n. 78, p. 242-256, maio-ago. 2009. 
SOUSA, J. V. Avaliação e regulação na educação superior brasileira: concepção, natureza e finalidades. In: CUNHA, C.; SOUSA, J. V.; SILVA, M. A. Universidade e Educação Básica: políticas e articulações possíveis. Brasília: Líber Editora; Faculdade de Educação/UnB, 2012.

SOUSA, J. V. Educação superior no Distrito Federal: consensos, conflitos e transformações na configuração de um campo. Brasília: Liber Livros, 2013.

SOUSA, J. V. Educação superior: evolução, organização e cenários. In: ROCHA, M. Z. B.; PIMENTEL, N. M. (Org.). Organização da educação brasileira: marcos contemporâneos. Brasília: Editora Universidade de Brasília, 2016. p. 349-388.

STEGER, M. B. A globalização: compreender. Vila Nova de Famalicão, Portugal: Edições Quasi, 2003.

UNIVERSIDADE FEDERAL DA INTEGRAÇÃO LATINO AMERICANA. Plano de Desenvolvimento Institucional PDI 2013-2017. Disponível em: <https://www.unila.edu.br/ sites/default/files/files/PDI\%20UNILA\%202013-2017.pdf>. Acesso em: 24 out. 2017.

UNIVERSIDADE FEDERAL DA INTEGRAÇÃO LATINO AMERICANA. Relato Institucional 2014. Disponível em: $<$ https://www.unila.edu.br/sites/default/files/files/RelatoInstitucional-Exerc\%C3\%ADcio-2014.pdf>. Acesso em: 18 out. 2017.

UNIVERSIDADE FEDERAL DA INTEGRAÇÃO LATINO AMERICANA. Relatório de Autoavaliação Institucional 2014. Disponível em: <https://www.unila.edu.br/sites/default/ files/files/relatorio $\% 20$ final $\% 20 \mathrm{CPA} \% 202014 \% 20 \mathrm{pdfpdf}>$. Acesso em: 23 out. 2017.

UNIVERSIDADE FEDERAL DE MINAS GERAIS. Plano de Desenvolvimento Institucional 2013-2017. Disponível em: $<$ https://www.ufmg.br/conheca/pdi_ufmg.pdf $>$. Acesso em: 18 out. 2017.

UNIVERSIDADE FEDERAL DE MINAS GERAIS. Relato Institucional 2016. Disponível em: < https://www.ufmg.br/ dai/textos/RELATO-INSTITUCIONAL-2017-07MARC.pdf>. Acesso em: 18 de out. 2017.

UNIVERSIDADE FEDERAL DE MINAS GERAIS. Relatório de Autoavaliação Institucional CPA/UFMG. 2015. Disponível em: <https://www.ufmg.br/dai/textos/relatorio-autoavaliacaoinstitucional-2015.pdf>. Acesso em: 19 out. 2017.

UNIVERSIDADE FEDERAL DE SANTA CATARINA. Plano de Desenvolvimento Institucional 2010 a 2014. Disponível em: <http://pdi.ufsc.br/files/2014/10/PDI-2010-2014-ComCapa-e-Indice.pdf $>$. Acesso em: 25 out. 2017.

UNIVERSIDADE FEDERAL DE SANTA CATARINA. Relatório de Autoavaliação Institucional da UFSC - Exercício de 2014. Disponível em: <http://cpa.ufsc.br/files/2014/09/ RELAT\%C3\%93RIO-CPA-2014.pdf>. Acesso em: 18 out. 2017.

UNIVERSIDADE FEDERAL DE SÃO PAULO. Plano de Desenvolvimento Institucional 2011-2015 - Revisado (2014). Disponível em: <https://www.unifesp.br/reitoria/proplan/ phocadownload/Documentos_PROPLAN/Documentos_PDI/ PDI_Reviso_Compilada.pdf $>$. Acesso em: 10 out. 2017.

UNIVERSIDADE FEDERAL DE SÃO PAULO. Relato Institucional. 2016. Disponível em: <http://www.unifesp.br/ reitoria/cpa/relatorios?download=29:2016-relato-institucionalprocesso-de-recredenciamento>. Acesso em 18 out. 2017.

UNIVERSIDADE FEDERAL DE SÃO PAULO. Relatório final de autoavaliação institucional 2014 [2015]. Disponível em: <http://www.unifesp.br/reitoria/cpa/relatorios? download=5:2015-relatorio-final>. Acesso em 22 out. 2017.

UNIVERSIDADE FEDERAL DO RIO GRANDE DO SUL. Plano de Desenvolvimento Institucional 2011-2015. Disponível em: <http://www.ufrgs.br/pdi/edicoes-anteriores/PDI2010 Dec4932010PDI.pdf>. Acesso em: 18 out. 2017.

UNIVERSIDADE FEDERAL DO RIO GRANDE DO SUL. Relatório de Autoavaliação da UFRGS 2014. Disponível em: <http://www.ufrgs.br/pdi/edicoes-anteriores/Relatorio deAvaliacaodoPDI20112015.pdf>. Acesso em: 23 out. 2017.

WORTHEN, B. R.; SANDERS, J. R.; FITZPATRICK, J. L. Avaliação de programas: concepções e práticas. São Paulo: Gente; Edusp; Instituto Fonte; Instituto Ayrton Senna, 2004.

Recebido em 30-10-2017. Aprovado em 20-12-2017. 